\title{
External Peer Review of Teaching (ExPeRT) Portfolios for Promotion
}

\author{
Chalmers, Denise and Partridge, Lee
}

University of Western Australia, Australia

\begin{abstract}
This paper focuses on the role and purpose of external expert peer review of teaching portfolios for promotion, using institutional criteria. This is grounded in the recognition that higher education institutions typically struggle to identify suitably experienced, expert reviewers of teaching portfolios for promotion purposes. It considers the feasibility of establishing a 'College of Peers' who are endorsed and trained teaching and learning experts to carry out the reviews. A model of training expert peer reviewers was trailed. While grounded in the Australian context, the issues and applications are international.
\end{abstract}

Keywords: Expert peer review, teaching portfolio, promotion 
This paper focuses on the role and purpose of external peer review of teaching, with a focus on reviewing portfolios for promotion using institutional criteria. It considers the feasibility of establishing a 'College of Peers' who are endorsed and trained teaching and learning experts to carry out the reviews. This is grounded in the recognition that higher education institutions typically struggle to identify suitably experienced, expert reviewers of teaching portfolios for promotion purposes.

The paper is organised in four parts. It:

1. Provides an overview of peer review in Australia, including an examination of models of contextually appropriate peer review from the literature

2. Identifies potential challenges including the recruiting of expert reviewers, engagement by the sector, and sustainability of the process

3. Outlines the characteristics upon which the ExPeRT model is based

4. Concludes with the outcomes of a trial of the training of experts for the purposes of promotion and recognition .

\section{Peer review in Australian higher education}

There has been strong advocacy and support for the use of peer review in the Australia higher education sector. For example, nationally funded studies and projects (Harris et al., 2008; Crisp et al., 2009; McKenzie et al., 2011; Wood et al., 2011; Sachs et al., 2013; Nash et al., 2014; Krause et al., 2014, Booth et al, 2015) have long promoted its use for both developmental and performative purposes. This reflects over 50 years of international advocacy that peers and colleagues should be considered as legitimate and valuable sources of information about teachers and teaching (Simpson, 1967; Hildebrand, 1971; Chalmers \& Hunt, 2016).

The Australian studies have focused on different aspects of peer review of teaching including classroom observation, online teaching, and assessment to ensure standards. The purpose of the reviews has been predominantly for teacher development and are conducted within institutions. Two studies have looked at external peer review (Crisp et al., 2009; Krause et al., 2014). The project by Crisp and colleagues (2009) on 'Peer Review of Teaching for Promotion Purposes' considered both within institution teacher observation and external peer review of documented evidence for evaluative purpose and trialled it across 4 universities. They concluded that "summative peer review of teaching has the ability to improve both the status and the quality of teaching at tertiary level, by encouraging the promotion of exceptional teachers and academics engaged in the scholarship of teaching at all levels" (2009, p 5). They recommended that "for a summative peer review of teaching program to be successful, peer reviewers must be trained and experienced" (2009, p 5). However, to date there has been little progress made on establishing and training a pool of teaching and learning experts that can be called on by 
universities to review teaching portfolios against institutional or external criteria for promotion purposes.

\subsection{Models of peer review}

Models of peer review of teaching can simplistically be categorised as internal or external and for summative or formative purposes. The benefits of external peer review have long been accepted and practiced (Conley-Tyler, 2005) in academia especially for summative purposes where independence of judgement is valued for research but has been met with active resistance for teaching (Shulman 1999; Gosling, 2014). It has been argued that internal peer review is better suited for formative purposes where a degree of familiarity of the reviewees and their practice can be an advantage in the provision of constructive feedback for improvement (Bell \& Cooper, 2013; Sachs et al., 2013; Nash et al., 2014).

These models are utilised for a variety of purposes and at varying levels across the higher education sector. They may be undertaken at a faculty, institutional or sector level and may be conducted for purposes such as institutional quality assurance of courses, accreditation of degrees, assessment standards and quality of teaching for the purposes of recognition and/or promotion.

While there is a natural alignment between external review for summative purposes and internal review for formative outcomes there are exceptions to this trend. The internalsummative model, is less common as it is contrary to the long established academic tradition of external examiners provision of unbiased assessment (Gaunt, 1999). There are however examples of this in cases such as institutional fellowships. There is an increasing number of examples of the external-formative model where external reviewers offer formative advice related to teaching, assessment and academic standards generally. In each of the examples of this type listed, a community of qualified assessors support the practice. Hybrid models also exist where both internal and external assessors work together for summative purposes, such as the HEA Fellowship, and for formative purposes such as the Peer Review Assessment Network (PRAN)

In reality, the dimensions and characteristics of a peer review model of teaching are more complex and include:

- Whether the reviewers are internal or external (including whether the review is blind)

- The purpose of the review (summative or formative)

- The knowledge and experience of the reviewers (including whether training of the reviewers occurs)

- The reviewing process (including the standards against which the review is conducted) 
Booth et al. (2015) advocate the adoption of a multi-level approach to peer review to meet the particular requirements of the HE sector. In the context of reviewing assessment, they propose a five-level approach, each level becoming more sophisticated and rigorous than the previous. Only the lowest level involves an internal review process within an institution. The next four levels incorporate external review with increasingly experienced reviewers. More recently a number of scholars (Bloxham and Price, 2015; Medland, 2015) have questioned the assumption that external review alone is sufficient to ensure rigour of judgement. They stress the need for external reviewers to be not only qualified and experienced but also trained in the process of review. Consequently, the highest level of review noted by Booth et al (2015) and exemplified by the Achievement Matters model involves trained assessors to ensure both quality and calibrated reviews enhancing the reliability and validity of the process.

Currently, the assessment of teaching quality by models such as those employed by the HEA Fellowship and academic promotional practices do not reach the highest level supporting reliability and validity of assessment (Booth et al., 2015). While reviewers in both cases are demonstrably expert teachers, by virtue of their institutional or association status, they are not specifically trained in the reviewing, assessing or moderating of other's practice. This highlights an apparent gap in the sector's mission to assure quality of teaching and learning.

This paper proposes a new model for the external peer review of teaching excellence against institutional or externally standards for the purpose of promotion or recognition. The model will be referred to as the ExPeRT (External Peer Review of Teaching) model.

\section{Challenges}

A number of obvious challenges are present in developing the ExPeRT model of peer review for academic promotion and recognition. These include the recruitment of experts, engagement by institutions and the sustainability of the process. Each of these will addressed in turn.

\subsection{Identifying and recruiting assessors and establishing a register of ExPeRTs}

External peer review processes necessitate the establishment of a community of reviewers that can be accessed to undertake reviews as required. These groups mostly consist of scholars who have demonstrated qualifications and experience. The groups are variously known by names such as College of Peer Observers (University of Queensland, 2015), Register of experts (TEQSA, 2012), and College of Peers (Peer Review of Assessment Networks, 2015).

The process of identifying potential assessors can be approached in a number of ways. A call for prospective assessors can be made across the sector as is done by TEQSA with 
applicants supplying their bona fides, and demonstrating their expertise to undertake the process. Experienced individuals may be invited to join the network of assessors. Existing groups, such as HERDSA, OLT Fellows or CADAD, that already undertake teaching and learning assessment may be asked to nominate potential assessors. The register of ExPeRTs then could be integrated in established frameworks by drawing on existing communities of assessors as a base.

The motivations for individual academics to join the register of ExPeRTs are likely to include a variety of aspects. Included amongst these is the recognition it carries, which is valuable for their own career progression; the professional development and networking opportunities it provides; and the desire to promote quality teaching and learning in the Australian HE sector.

Digital platforms such as PRAN or Spark Plus®, which is used by the Assessment Matters project, could be utilised to home and manage the ExPeRT group and process.

\subsection{Engagement by institutions}

For the ExPeRT model to gain acceptance it needs to have buy-in either by individual institutions or by the sector as a whole. To consider why institutions might engage with this model it is useful to examine the value proposition being offered. Currently, institutions frequently struggle to find appropriate assessors for the teaching and learning components of academic portfolios for promotion. Assessors that are identified tend not to be trained through processes of calibration or moderation. It is not unreasonable in these circumstances to question the reliability and validity of judgement.

The EXPERT model of peer review being proposed would provide a ready source of not only experienced but also trained reviewers. The current alternatives fall far short of the proposed model leaving considerable gaps in the sector's quality assurance.

\subsection{Sustainability of the process}

The proposed ExPeRT model is most likely to be sustainable if adopted by an existing group such as HERDSA, CADAD or OLT Fellows to administer as core business for their association. The provision of this resource could be structured as a fee-for-service business model along the lines of the services offered by the HEA thereby enhancing its sustainability.

\section{Characteristics of model}

The following characteristics underpin this proposed ExPeRT model of peer review of teaching: 
- Quality is paramount in the operation of the ExPeRT model. As such reviewers must demonstrate their record in the area of teaching and learning excellence before they can join the register of ExPeRTs.

- External review is central to this model, helping support ethical considerations including the reduction of bias is assessments.

- Training of assessors is the key characteristic which sets this model apart from existing forms of peer review of teaching. Both initial (calibration) training and ongoing (moderation) processes will be employed to ensure the continued rigour of the model.

- $\quad$ Sustainability must be established and ensured to maintain the process as a key component of quality assurance in the Australian HE Sector.

- Relevance, such that the peer review process is flexible and fit-for-purpose is paramount. The ExPeRT model will provide reviewers that can rigorously assess teaching and learning quality against a range of criteria.

\section{Trialling the ExPeRT training of assessors}

A pilot training program for the ExPeRT model was conducted in June 2017 with an invited group of senior academics from across the Australian HE sector. The process trialled was as follows:

1. Assessors were invited to attend a half day workshop in Sydney.

2. Participants were sent de-identified teaching portfolios submitted in support of academic promotion and the criteria against which they were to be assessed. Reviewers were asked to assess the portfolios and submit their assessment prior to meeting.

3. Participants reviewed others' assessments and compared them with their own at the workshop.

4. The workshop procedure was modelled on the the 'Assessment Matters' calibration process to bring assessors to a common and agreed position on each portfolio.

5. The participants' comments and suggestion for improving the process and supporting its ongoing sustainability were sought.

6. Following the calibration workshop, participants were sent an additional portfolio to review and submit an assessment.

7. Plans to expand the ExPeRT model for a second round of recruitment and training were formulated. 


\section{Conclusion}

This paper has argued for the establishment of an ExPeRT (External Peer Review of Teaching) model in the Australian higher education context for the purposes of assessing academic promotion and recognition against either institutional criteria or external criteria. The key themes that have arisen for consideration include that 1) the model be based on the principle of quality, which is achieved through the provision of external reviewers who have been trained to ensure a calibrated assessment; 2) the success of the model relies on the individual or collective buy-in of HE institutions and; 3) ownership of the model should be established to ensure its growth and sustainability into the future. It is argued that if quality teaching and learning in higher education is important, these themes must be actively fostered.

\section{References}

Barnard, A., Nash, R., Bolt, S., Shannon, S., McEvoy, K., Waters, C. \& Rochester, S. (2014). Developing a culture of peer review of teaching through a distributive leadership approach.

Bell, M., \& Cooper, P. (2013). Peer observation of teaching in university departments: A framework for implementation. International Journal for Academic Development. $18(1), 60-73$

Bloxham, S., \& Price, M. (2015). External examining: fit for purpose? Studies in Higher Education, 40(2), pp.195-211.

Booth, S., Beckett, B., Saunders, C., Freeman, M., Alexander, H., Oliver, R., Thompson, M., Fernandez, J. \& Valore, R. (2015). Peer review of assessment networks: Sectorwide options for assuring and calibrating achievement standards within and across disciplines and other networks. Report prepared for the Office for Learning and Teaching, Australia Government.

Chalmers, D. (2017). Recognising and rewarding teaching: Australian teaching standards and expert peer review. OTL National Senior Teaching Fellowship. www.recognisinguniteaching.edu.au

Chalmers D., \& Hunt, L. (2016). Evaluating teaching. HERSDA Review of Higher Education, 3, 25-55. http://herdsa.org.au/herdsa-review-higher-education-vol-3/25-55

Conley-Tyler, M. (2005). A fundamental choice: internal or external evaluation? Evaluation Journal of Australasia, 4(1/2), 3.

Crisp, G., Sadler, R., Krause, K. L., Buckridge, M., Wills, S., Brown, C., \& Brougham, B. (2009).Peer Review of Teaching for Promotion Purposes: Final Project Report. Australian Learning and Teaching Council. 
Gaunt, D. (1999). The Practitioner as External Examiner. Quality in Higher Education, 5(1). pp.81-90.

Gosling, D. (2014). Collaborative peer supported review of teaching. In J. Sachs \& M. Parsell, M. (Eds) Peer review of learning and teaching in higher education: International perspectives pp.13-31. Professional Learning and Development in Schools and Higher Education. 9, Dordrecht: Springer.

Harris, K-L., Farrell, K., Bell, M., Devlin, M., \&James, R. (2008). Peer review of teaching in Australian higher education: A handbook to support institutions in developing an embedding effective policies and practices. Sydney, NSW: Office for Learning and Teaching. http://www.olt.gov.au/resource-peer-review-of-teaching-melbourne-2009 .

Higher Education Research and Development Society of Australasia (HERDSA) http://herdsa.org.au/

Hildebrand, M., Wilson, R.C., \& Dienst, E.R. (1971). Evaluating university teaching. University of California, Berkeley: Centre for Research and Development in Higher Education.

Krause, K., Scott, G., Aubin, K., Alexander, H., Angelo, T., Campbell, S., Carroll, M., Deane, E., Nulty, D., Pattison, P., Probert, B., Sachs, J., Solomonides, I., Vaughan, S. (2013). Assuring final year subject and program achievement standards through interuniversity peer review and moderation. www.uws.edu.au/latstandards.

McKenzie, J, \& Parker, N. (2011). Peer review in online and blended learning environment. http://www.uts.edu.au/sites/default/files/final-report.pdfonments. ALTC project, University of Technology Sydney. http://www.uts.edu.au/sites/default/files/final-report.pdf

Medland, E. (2015). Examining the assessment literacy of external examiners. London Review of Education, 13(3), pp. 21-33.

Nash, R., and Barnard, A. (2014). Developing a culture of peer review of teaching through a distributive leadership approach. Sydney, NSW: Office for Learning and Teaching. http://www.olt.gov.au/resource-library

Nash, R., Bolt, S., Barnard, A., Rochester, S. Mcevoy, K., Shannon, S. \& Philip, R. (2014). Developing a culture of peer review of teaching through a distributive leadership approach. Sydney, NSW: Office for Learning and Teaching. http://www.olt.gov.au/project-developing-culture-peer-review-teaching-throughdistributive-leadership-approach-2011.

Peer Review of Assessment Network (PRAN) http://www.utas.edu.au/curriculum-andquality/quality/external-referencing/peer-review/pra-network

Sach, J., \& Parsell, M. (2014) Introduction: The place of peer review in learning and teaching. In J. Sachs \& M. Parsell.(eds). Peer review in learning and teaching in higher education: International perspectives. Springer, Dordrecht. p.1-12. 
Sachs, J., Parsell, M., Ambler, T., Cassidy, S., Homewood, J., Solomonides, I., et al. (2013). Social, communicative and interpersonal leadership in the context of peer review. Sydney, NSW: Office for Learning and Teaching. http://www.olt.gov.au/project-social-communicative-interpersonal-leadership$\underline{\text { macquarie-2009 }}$

Shulman, L. (1993). Teaching as community property: Putting an end to pedagogical solitude. Change: The Magazine of Higher Learning, 25, (6), 6-7.

Simpson, R.H. (1967). Evaluation of college teachers and teaching, Journal of Farm Economics, 49 (1) Part 2, 286-298.

Watty, K., M. Freeman, B. Howieson, P. Hancock, B. O’Connell, P. De Lange \& A. Abraham (2014). Social moderation, assessment and assuring standards for accounting graduates. Assessment \& Evaluation in Higher Education. 39(4) pp. 461-478.

Wood, D, Scutter, S., \& Wache, D., (2011) Peer Review of Online Learning and Teaching University of South Australia. Sydney, NSW: Office for Learning and Teaching http://www.communitywebs.org/peer_review/ 